\title{
Liver in ulcerative colitis: Obstructive jaundice due to bile duct carcinoma
}

\author{
J. G. RANKIN, ${ }^{1}$ A. P. SKYRING, AND S. J. M. GOULSTON \\ From the A. W. Morrow Department of Gastroenterology, ${ }^{2}$ \\ Royal Prince Alfred Hospital, Sydney, Australia
}

SYNOPSIS In a series of 441 patients with ulcerative colitis, three patients were found to have bile duct carcinoma. The frequency of the association of the two diseases in this and other series suggests a specific relationship, the basis of which is still undetermined.

Obstructive jaundice in patients with ulcerative colitis is usually due to pericholangitis, which develops without blockage to the major bile ducts, and may or may not be accompanied by cirrhosis (Kleckner, Stauffer, Bargen, and Dockerty, 1952; Boden, Rankin, Goulston, and Morrow, 1959; Stauffer, Sauer, Dearing, and Baggenstoss, 1965). The main hepatic lesion in such cases consists of portal and periportal inflammation in which, it has been suggested, the inflammatory changes may originate in either the terminal radicles of the portal vein or the biliary epithelium (Boden et al., 1959; McCarthy and Read, 1962). Coincidental, but apparently unrelated, obstructive diseases of the extrahepatic biliary tree have also been reported occasionally in patients with ulcerative colitis. There have been cases of bile duct stricture with and without gallstones (Case Records of the Massachusetts General Hospital, 1954; Ross and Swartz, 1948; Goldgraber and Kirsner, 1960; Case Records of the Massachusetts General Hospital, 1964), choledocholithiasis (Comfort, Bargen, and Morlock, 1938), and bile duct carcinoma (Parker and Kendall, 1954).

It has also been suggested that bile duct carcinoma may be a complication of, or specifically associated with, ulcerative colitis (Boden et al., 1959; Rankin, 1962), and further recent reports appear to support this view (Edwards and Truelove, 1964; Palmer, Kirsner, Goldgraber, and Fuentes, 1964; Stauffer et al., 1965). The three cases recorded in the present paper strengthen the association whatever its nature.

\section{CASE REPORTS}

CASE 1 (007350) This 21-year-old woman had an ile-

${ }^{1}$ Present address: University of Melbourne, Department of Medicine, St. Vincent's Hospital, Melbourne, Australia

'Supported by a grant from the Bushell Trust ostomy performed in June 1954 and a proctocolectomy the following October because of ulcerative colitis. The disease, which had been present for 14 years, caused chronic ill health and recurrent iron-deficiency anaemia. The changes of chronic ulcerative colitis with pseudopolyposis were found in the resected bowel.

In August 1955, she presented with painless obstructive jaundice of seven weeks' duration: the serum bilirubin level was $21 \mathrm{mg}$. per $100 \mathrm{ml}$., serum alkaline phosphatase

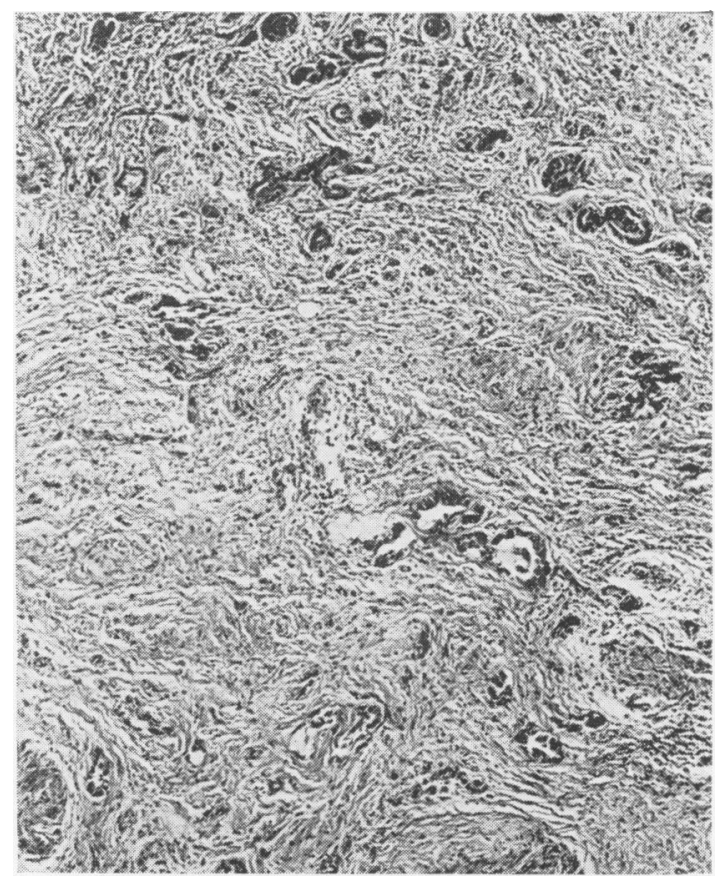

FIG. 1. Photomicrograph of bile duct stricture (case 1) showing an adenocarcinoma with marked fibrous tissue reaction. 
41 King-Armstrong (K.A.) units per $100 \mathrm{ml}$., thymol flocculation $1+$, and zinc-sulphate turbidity 6 units (normal range 2 to 6 units). No previous liver function test results were available. At exploratory laparotomy the gall bladder was found to be collapsed and no extrahepatic biliary obstruction could be demonstrated; operative choledochography was not performed. The histological changes of biliary obstruction and early cirrhosis were observed in an operative liver biopsy. After operation jaundice persisted, the serum bilirubin level fluctuating between 15 and $23 \mathrm{mg}$. per $100 \mathrm{ml}$., while the serum alkaline phosphatase level rose from 43 to 90 K.A. units per $100 \mathrm{ml}$. and serum cholesterol from 840 to $1,050 \mathrm{mg}$. per $100 \mathrm{ml}$. over the next four months. Steatorrhoea was observed during this period. She died on 2 December 1955, six days after a laparotomy for intestinal obstruction due to adhesions. At that time her blood urea level had risen to $234 \mathrm{mg}$. per $100 \mathrm{ml}$.

At necropsy the common hepatic duct was obstructed by a fibrous stricture for $1 \mathrm{~cm}$. above its junction with the cystic duct. Histological examination showed this stricture to consist of a bile duct carcinoma with marked fibrosis (Fig. 1). The liver was enlarged $(3,770$ g.) and finely granular; the histological changes were those of cirrhosis and biliary obstruction. Microscopic sarcoidlike granulomata were an unexpected finding in the lungs.

CASE 2 (052971) Jaundice first occurred in this man at 46 years of age, a few months after the onset of symptoms of ulcerative colitis. Exploratory laparotomy at that time failed to demonstrate extrahepatic biliary obstruction. Over the next year diarrhoea persisted, jaundice was recurrent, and the patient needed several blood transfusions for recurrent anaemia. Splenectomy was then performed because of a clinical diagnosis of haemolytic anaemia, but without supportive laboratory evidence for such a disorder. For the next seven years he remained well except for two exacerbations of colitis. Diarrhoea and jaundice then recurred and a cholecystectomy was performed for non-calculus cholecystitis.

He first attended the Royal Prince Alfred Hospital in Jailuary 1956, 14 months after cholecystectomy, when he was aged 55 years. On admission the serum bilirubin level was $0.2 \mathrm{mg}$. per $100 \mathrm{ml}$., serum alkaline phosphatase 24 K.A. units per $100 \mathrm{ml}$., thymol-flocculation $1+$, and zincsulphate turbidity 5 units. A week later he had an episode of cholangitis during which the serum bilirubin level rose to $5 \mathrm{mg}$. per $100 \mathrm{ml}$. and alkaline phosphatase to $48 \mathrm{~K}$.A. units per $100 \mathrm{ml}$. Although a few small pigmented stones were found when the common bile duct was explored, they appeared too small to cause obstructive jaundice. An operative choledochogram failed to demonstrate extrahepatic biliary obstruction, but was suggestive of slight dilatation of the main right hepatic duct.

The patient remained symptomatically well until jaundice recurred in September 1957, when the serum bilirubin level was $21 \mathrm{mg}$. per $100 \mathrm{ml}$., alkaline phosphatase $78 \mathrm{~K}$.A. units per $100 \mathrm{ml}$., thymol flocculation negative, and zinc sulphate turbidity 8 units. At operation no extrahepatic biliary obstruction was demonstrated; a choledochoduodenostomy was performed and the common bile duct drained with a T-tube. Microscopically

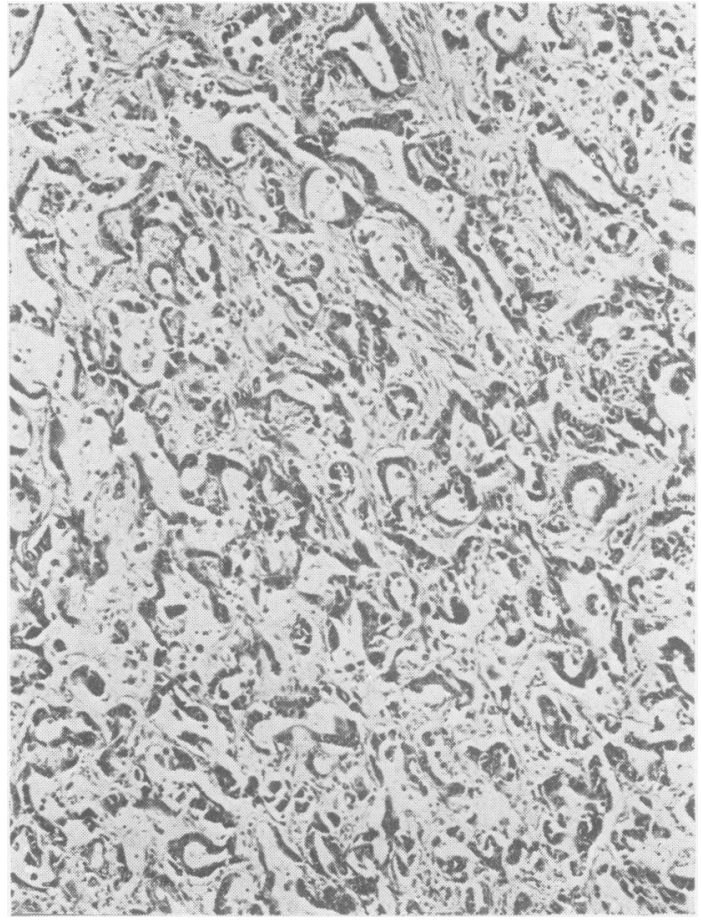

FIG. 2. Photomicrograph of intrahepatic bile duct carcinoma (case 2).

the changes observed in an operative liver biopsy were those of biliary obstruction and cirrhosis. Post-operatively he became more jaundiced and developed renal failure. The serum bilirubin level reached a value of 46 mg. per $100 \mathrm{ml}$. and blood urea $346 \mathrm{mg}$. per $100 \mathrm{ml}$. on 10 October, the day he died.

The extrahepatic biliary tree was found to be freely patent at necropsy. The liver was enlarged $(2,400 \mathrm{~g}$.): in the right lobe there was a tumour mass, $5 \mathrm{~cm}$. in diameter, which surrounded the right hepatic duct and a few similar but smaller lesions which occurred particularly around the main tumour. Histologically the neoplasm was a bile duct carcinoma (Fig. 2) with metastatic deposits in the lower lobes of both lungs and in the lymph nodes of the porta hepatis and para-aortic region.

CASE 3 (077126) In December 1958, at the age of 18 years, this young woman, who had a 10-year history of ulcerative colitis, had an ileostomy and proctocolectomy performed. At operation the disease was found to involve the terminal ileum and all the large intestine. In addition there was an undifferentiated carcinoma encircling the colon at the splenic flexure (Fig. 3). There were no metastases in the regional lymph nodes. At this time there was no clinical or biochemical evidence of hepato-biliary disease. Subsequently the patient was well until March 1960 , when she was readmitted with intestinal obstruction due to peritoneal adhesions. These were divided at 


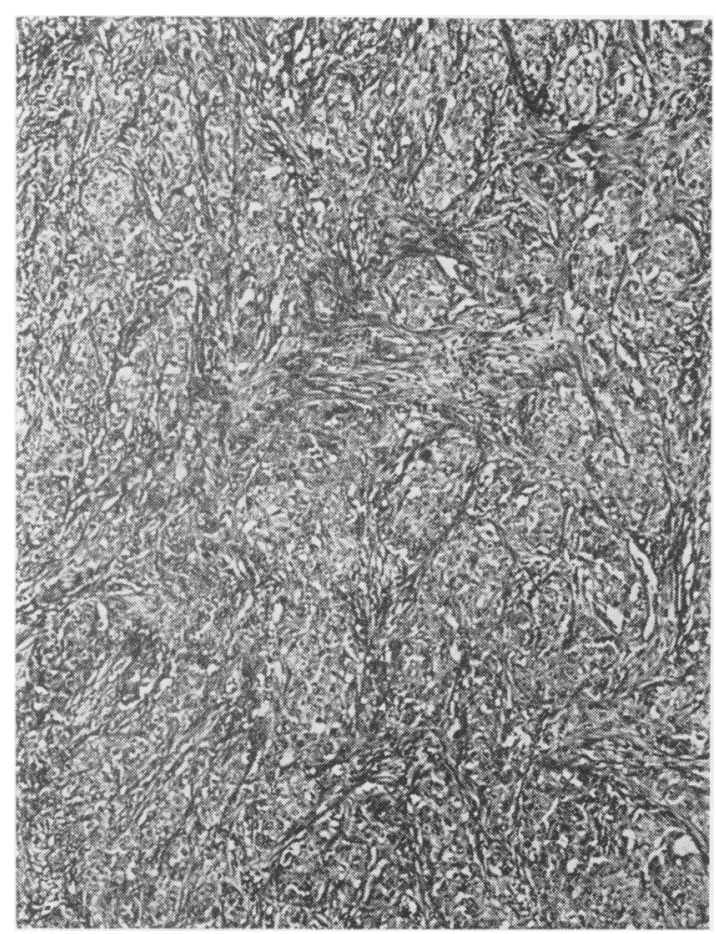

FIG. 3 .

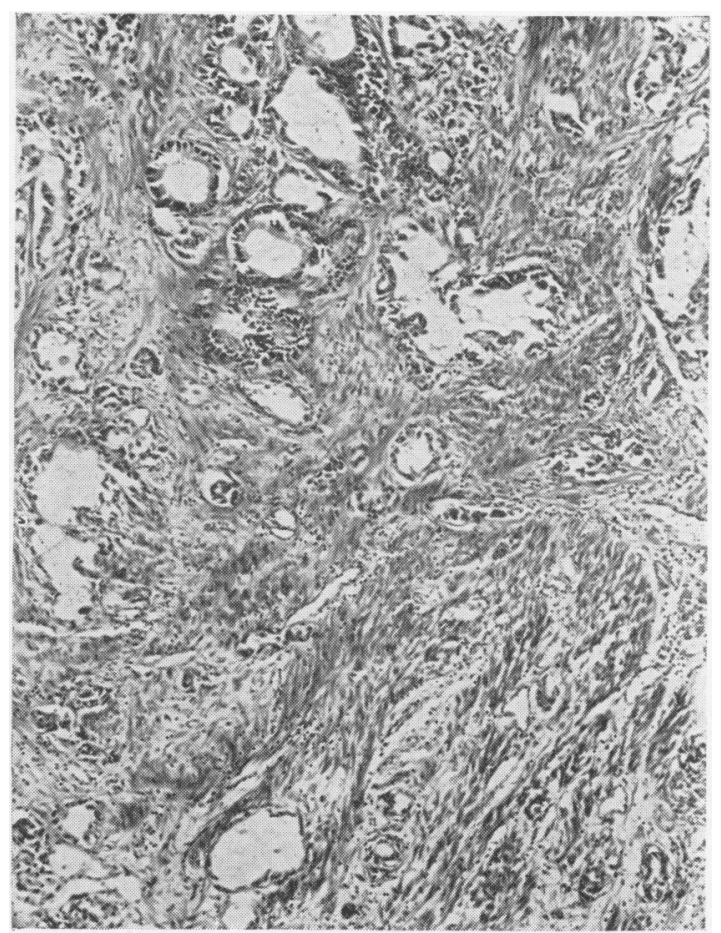

FIG. 4.

FIG. 3. Photomicrograph of anaplastic carcinoma of the colon (case 3).

FIG. 4. Photomicrograph of bile duct stricture (case 3) showing an adenocarcinoma and marked fibrosis. This tumour had no microscopic resemblance to the colonic carcinoma (Fig. 3).

laparotomy and at this time no tumour deposits were observed in the abdomen.

In June 1960, she presented with painless obstructive jaundice; the liver was enlarged $2 \mathrm{~cm}$. below the right costal margin and the gall bladder was palpable. Liver function tests at that time were: serum bilirubin level 16 mg. per $100 \mathrm{ml}$., serum alkaline phosphatase 37 K.A. units per $100 \mathrm{ml}$., thymol flocculation $1+$, and zinc sulphate turbidity 10 units. At laparotomy the common bile duct was found to be surrounded by firm enlarged lymph nodes; the obstructed gall bladder was anastomosed to the duodenum. Jaundice was unrelieved by this operation and over the subsequent months xanthelasma developed and the liver increased in size. The results of investigations in December 1960 were: serum bilirubin level 15.5 mg. per $100 \mathrm{ml}$, serum alkaline phosphatase 75 K.A. units per $100 \mathrm{ml}$., thymol flocculation test negative, zinc sulphate turbidity 11 units, serum cholesterol $525 \mathrm{mg}$. per $100 \mathrm{ml}$., and stool fat excretion $47.5 \mathrm{gm}$. per day.

She was readmitted in December with epigastric pain and melaena, and on barium swallow examination was found to have oesophageal varices. From then until March 1961 she suffered recurrent gastrointestinal bleeding and developed ascites and venous collaterals on the anterior abdominal wall. A further laparotomy was performed in the hope of relieving biliary obstruction. Unfortunately this procedure was technically impossible and she died a week after operation.

At necropsy the cystic and common bile ducts were surrounded by fibrous tissue at their junction and were dilated above this area. Microscopically the tissue from this region was involved by a bile duct carcinoma (Fig. 4) which bore no resemblance to the original colonic tumour. Both liver and spleen were enlarged, the former weighing $2,635 \mathrm{~g}$. There were numerous metastatic deposits of the bile duct carcinoma around the gall bladder, in the head of the pancreas, and in the lymphatic glands of the porta hepatis and para-aortic regions. Oesophageal varices were present.

\section{DISCUSSION}

During the period 1949 to 1964 a series of 441 patients with ulcerative colitis has been observed at the Royal Prince Alfred Hospital. Three of these patients, whose clinical details have been reported in this paper, also suffered from carcinoma of the bile duct epithelium. In the same series, pericholangitis, which occurred in 26 patients, was the most common significant hepatic lesion. Carcinoma of the extrahepatic bile ducts, other than primary lesions of the 
ampulla of Vater, are uncommon tumours. Sako, Seitzinger, and Garside (1957) accepted only 570 reported cases and cited another 147 in which there was no histological confirmation of the diagnosis. In the Australian State of Victoria bile duct tumours are rare. They account for approximately $0.4 \%$ of the non-cutaneous malignant neoplasms and have an annual incidence in the population of 0.8 per 100,000 (Keogh, 1964). Intrahepatic cholangiocarcinoma is also an infrequent tumour in temperate climates, where the annual reported incidence at necropsy averages about $0.6 \%$ (Greene, 1939). Although they arise from the same epithelium and usually have no particular histological features by which they can be differentiated, intra- and extrahepatic bile duct carcinomata are usually considered separately. Such a division appears to be arbitrary.

Ulcerative colitis is also an uncommon disease. No figures are available for its incidence in Australia. However, in New Zealand, which has racial, cultural, and geographical similarities to Australia, the estimated mean annual occurrence of new cases among the non-Maori population is between 5 and 6 per 100,000 and the prevalence 41.4 per 100,000 (Wigley and Maclaurin, 1962). Therefore, the occurrence reported in this paper, of three patients with bile duct carcinoma out of a total series of 441 patients with ulcerative colitis, is striking and suggests a specific association. Further evidence favouring this view is the observation that two of the patients (cases 1 and 3) died from carcinoma of the bile ducts at the unusually early age of 22 years. In the cases reviewed by Sako et al. (1957) the ages of the female patients ranged from 23 to 82 years, with a mean of 56.7 years. Nevertheless, the statistical significance of an apparent association between two uncommon diseases is difficult to assess (Cornes, 1960).

The three patients had suffered from colitis for from 10 to 14 years before clinical evidence of bile duct carcinoma occurred. In cases 1 and 3 clinical evidence of tumour appeared nine and 18 months respectively after colectomy. However, because of the slow-growing characteristics of bile duct carcinoma, it is likely that in each instance the tumour was present at the time of colectomy. In two patients (cases 1 and 3), the lesion was situated at the lower end of the common hepatic duct, whilst the third patient (case 2) had an intrahepatic cholangiocarcinoma arising from the right hepatic duct. In case 3 there is the possibility that the bile duct tumour was a metastasis from the antecedent colonic carcinoma. However, the histological appearance of the biliary lesion and its apparent metastatic deposits in the regional lymph nodes and pancreas was that of a well-differentiated adenocarcinoma with marked fibrosis (Fig. 4). By contrast, the primary colonic tumour was an anaplastic carcinoma (Fig. 3) without apparent metastases.

Previously, Parker and Kendall (1954) have reported one patient with a bile duct carcinoma and ulcerative colitis, Palmer et al. (1964) two patients with this combination out of a total of 720 patients with ulcerative colitis, and Edwards and Truelove (1964) three out of 624 patients. In a recent report of 30 cases of chronic ulcerative colitis with associated hepatic disease, Stauffer et al. (1965) noted one case of cholangiocarcinoma and one of carcinoma of the gall bladder. Edwards and Truelove (1964) suggested that there may be significance in the finding in their series of nine cases of carcinoma involving various parts of the digestive system apart from carcinoma of the colon. They believe that this may be due to a widespread disturbance of the digestive tract in ulcerative colitis.

The association of bile duct carcinoma and ulcerative colitis may be fortuitous. However, if this is not so there are several possible explanations. The relationship may be genetically determined, as appears to be the case with ankylosing spondylitis and ulcerative colitis (McBride, King, Baikie, Crean, and Sircus, 1963). Alternatively, bile duct carcinoma may be a complication of ulcerative colitis and possibly related to the inflammatory changes found in the biliary epithelium of many patients with the latter disease. In only one patient (case 2) reported in the present paper was there any evidence to support a diagnosis of antecedent hepato-biliary pathology.

Although bile duct carcinoma may seem a strange association with ulcerative colitis, it is not the only unusual form of cancer which has been described in the latter disease, for of the 19 cases of primary lymphoma of the large bowel reviewed by Cornes, Smith, and Southward (1961), seven were found to have suffered from chronic ulcerative colitis also.

In conclusion, it is emphasized that obstructive jaundice occurring in patients with ulcerative colitis presents particular difficulties in both diagnosis and management. This clinical picture may be caused by unrelated biliary disease or those lesions of the intraand extrahepatic biliary tract which appear to be specifically associated with ulcerative colitis, namely, pericholangitis, inflammatory bile duct stricture, and carcinoma.

\section{SUMMARY}

In a series of 441 patients with ulcerative colitis, three patients were found to have bile duct carcinoma The frequency of the association of the two diseases in this and other series suggests a specific relationship, the basis of which is still undetermined. 


\section{REFERENCES}

Boden, R. W., Rankin, J. G., Goulston, S. J. M., and Morrow, W. (1959). The liver in ulcerative colitis. The significance of raised serum-alkaline-phosphatase levels. Lancet, 2, 245-248.

Case Records of the Massachusetts General Hospital. Case 40491. (1954). New Engl. J. Med., 251, 983-988.

- Case 4. 1964 (1964). Ibid., 270, 199-206.

Comfort, M. W., Bargen, J. A., and Morlock, C. G. (1938). The association of chronic ulcerative colitis (colitis gravis) with hepatic insufficiency: report of four cases. Med. Clin. N. Amer., 22, 1089-1097.

Cornes, J. S. (1960). Multiple primary cancers: primary malignant lymphomas and carcinomas of the intestinal tract in the same patient. J. clin. Path., 13, 483-489.

—- Smith, J. C., and Southward, W. F. W. (1961). Lymphosarcoma in chronic ulcerative colitis with report of two cases. Brit. J. Surg., 49, 50-53.

Edwards, F. C., and Truelove, S. C. (1964). The course and prognosis in ulcerative colitis. III. Complications. Gut, 5, 1-22.

Goldgraber, M. B., and Kirsner, J. B. (1960). Chronic granulomatous cholecystitis and chronic fibrosing choledochitis associated with chronic ulcerative colitis. A case report. Gastroenterology, 38, 821-828.

Greene, J. M. (1939). Primary carcinoma of the liver. A ten year collective review. Int. Abstr. Surg., 69, 231-236.

Keogh, E. V. (1964). Personal communication.
Kleckner, M. S. Jr., Stauffer, M. H., Bargen, J. A., and Dockerty, M. B. (1952). Hepatic lesions in the living patient with chronic ulcerative colitis as demonstrated by needle biopsy. Gastroenterology, 22, 13-33.

McBride, J. A., King, M. J., Baikie, A. G., Crean, G. P., and Sircus, W. (1963). Ankylosing spondylitis and chronic inflammatory diseases of the intestines. Brit. med. J., 2, 483-486.

McCarthy, C. F., and Read, A. E. (1962). Bleeding esophageal varices in ulcerative colitis. Gastroenterology, 42, 325-329.

Palmer, W. L., Kirsner, J. B., Goldgraber, M. B., and Fuentes, S. S. (1964). Diseases of the liver in chronic ulcerative colitis. Amer. J. Med., 36, 856-866.

Parker, R. G. F., and Kendall, E. J. C. (1954). The liver in ulcerative colitis. Brit, med. J., 2, 1030-1032.

Rankin, J. G. (1962). Systemic manifestations of ulcerative colitis. Bull. post-grad. Comm. Med. Univ. Syd., 17, 288-294.

Ross, J. R., and Swartz, J. M. (1948). Hepatic dysfunction and cirrhosis in chronic ulcerative colitis. Gastroenterology, 10, 81-95.

Sako, K., Seitzinger, G. L., and Garside, E. (1957). Carcinoma of the extrahepatic bile ducts. Review of the literature and report of six cases. Surgery, 41, 416-437.

Stauffer, M. H., Sauer, W. G., Dearing, W. H., and Baggenstoss, A. H. (1965). The spectrum of cholestatic hepatic disease. J. Amer. med. Ass., 191, 829-837.

Wigley, R. D., and Maclaurin, B. P. (1962). A study of ulcerative colitis in New Zealand, showing a low incidence in Maoris. Brit. med. J., 2, 228-231. 